\title{
Tsunami early warning and decision support
}

\author{
T. Steinmetz, U. Raape, S. Teßmann, C. Strobl, M. Friedemann, T. Kukofka, T. Riedlinger, E. Mikusch, and S. Dech \\ German Aerospace Center (Deutsches Zentrum für Luft- und Raumfahrt, DLR), Oberpfaffenhofen, Germany
}

Received: 22 April 2010 - Revised: 19 August 2010 - Accepted: 19 August 2010 - Published: 6 September 2010

\begin{abstract}
An innovative newly developed modular and standards based Decision Support System (DSS) is presented which forms part of the German Indonesian Tsunami Early Warning System (GITEWS). The GITEWS project stems from the effort to implement an effective and efficient Tsunami Early Warning and Mitigation System for the coast of Indonesia facing the Sunda Arc along the islands of Sumatra, Java and Bali. The geological setting along an active continental margin which is very close to densely populated areas is a particularly difficult one to cope with, because potential tsunamis' travel times are thus inherently short. National policies require an initial warning to be issued within the first five minutes after an earthquake has occurred. There is an urgent requirement for an end-to-end solution where the decision support takes the entire warning chain into account. The system of choice is based on pre-computed scenario simulations and rulebased decision support which is delivered to the decision maker through a sophisticated graphical user interface (GUI) using information fusion and fast information aggregation to create situational awareness in the shortest time possible. The system also contains risk and vulnerability information which was designed with the far end of the warning chain in mind - it enables the decision maker to base his acceptance (or refusal) of the supported decision also on regionally differentiated risk and vulnerability information (see Strunz et al., 2010). While the system strives to provide a warning as quickly as possible, it is not in its proper responsibility to send and disseminate the warning to the recipients. The DSS only broadcasts its messages to a dissemination system (and possibly any other dissemination system) which is operated under the responsibility of BMKG - the meteorological, climatological and geophysical service of Indonesia - which also hosts the tsunami early warning center. The system is to be seen as one step towards the development of a "system of systems" enabling all countries around the Indian Ocean to have such early warning systems in place. It is
\end{abstract}

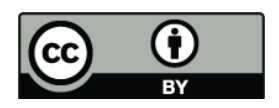

Correspondence to: T. Steinmetz (tilmann.steinmetz@dlr.de) within the responsibility of the UNESCO Intergovernmental Oceonographic Commission (IOC) and in particular its Intergovernmental Coordinating Group (ICG) to coordinate and give recommendations for such a development. Therefore the Decision Support System presented here is designed to be modular, extensible and interoperable (Raape et al., 2010).

\section{Introduction}

The occurrence and after-effects of the vast tsunami on 26 December 2004 in the Indian Ocean which killed almost one quarter of a million people in Southeast Asia set the scene for a large scale effort of various German and Indonesian research institutions in tsunami research. It deals with the possibilities of issuing an effective early warning using newly developed sensor, modelling and assessment frameworks (Rudloff et al., 2009). The work is funded by the German Federal Ministry of Education and Research (BMBF).

This paper describes the challenge of very short warning times for the particular geological setting of near-field tsunamis, the DSS and the underlying sensor system input as a technical solution and the principles the DSS is based on.

The overall design is based on a network of terrestrial and marine sensors specifically installed for this purpose. Databases of pre-computed tsunami scenario simulations, primary topographic data and last but not least the Decision Support System comprising the rule base, databases and easy-to-use Graphical User Interface (GUI), enable the decision maker (called Chief Officer on Duty, COOD) to make a quick and concise assessment of the situation at hand and immediately configure the required warning messages.

Using fast information fusion and aggregation, this GUI can thus be used by a single skilled user to take the decision whether or not to send and disseminate a warning in a timely manner. The DSS will also assess every change of situation as it is detected by any of the individual sensor systems and it reacts dynamically to those changes by compiling

Published by Copernicus Publications on behalf of the European Geosciences Union. 
and visualizing a new warning configuration every time the situation changes. It then configures and creates warning messages in pre-defined formats when the user decides to be "ready for dissemination". It is up to external dissemination systems upheld by BMKG to disseminate the warnings to pre-configured receivers.

\section{Challenge of tsunami early warning in Indonesia}

The particular geo-tectonic setting of the densely populated Indonesian islands of Sumatra, Java and Bali along the Sunda active continental margin causes the travel time of potential tsunami waves caused by an earthquake to the Indonesian coastline to be very short. The arrival of such waves can in many cases be estimated to be only some 20$40 \mathrm{~min}$ after the earthquake. This fact and the general lack of sensor technology which is able to directly detect and measure a tsunami as a spatially distributed phenomenon require using pre-computed tsunami simulation scenarios in combination with the best available sensor technology measuring seismicity as well as additional physical quanities like, amongst others, crustal dislocation vectors from precise GPS measurements .

In order to achieve a fast assessment of the situation it is necessary to assess those multiple different and mutually independent data sources in parallel (Lauterjung et al., 2010). The pre-computed scenarios depict the estimated time of arrival (ETA), the estimated wave height (EWH) at the coast, as well as the inundation length and height which can then be used to compare them with a-priori knowledge (e.g. regarding the vulnerability in certain parts of the affected coast) and analysis results from real-time information from the different sensor types. The GITEWS Decision Support System (DSS) described here serves as the backbone to allow an assessment for the tsunami threat - based on a comparison of live observations and pre-computed simulations - at the earliest time possible and to support the decision maker whether to issue a tsunami warning or not.

Unlike classical decision support problems, the process of combining spatial sensor and additional information, generating spatial and temporal situational awareness and assessing and proposing decision options is a process which evolves only slowly in the course of an event happening: due to the fact that sensor information becomes available in a non-deterministic sequence, initially with considerable uncertainties, in arbitrary order and with major information gaps, uncertainties will oftentimes still be present when deadlines for warning decisions are reached. The Chief Officers on Duty, who generally work in shifts to fulfil 24/7 operations' requirements, will often be required to meet this deadline even though they may not be skilled users of the individual sensors' analysis software or specifically trained in the required knowledge domains like crustal deformation monitoring using CGPS, sea-surface anomalies' measurements or the interpretation thereof.
The system aims at being easy and fast to use even under high time and mental pressure in order to make decisions regarding spatially discontinuous warnings easier and faster whilst meeting highest reliability demands.

\section{The early warning and mitigation system}

GITEWS uses a combination of sensor systems in a flexible and extensible observation and simulation framework which provide input to the decision support system (DSS) for information fusion in order to make situation assessments and generate decision proposals.

\subsection{Component description}

The individual sensor systems are:

1. The seismic detection and analysis systems build upon a dense seismometer/accelerometer network throughout the country and abroad as well as an analysis software (SeisComP3) which is used by seismic operators to find a solution for the source parameters of an earthquake like location, depth and magnitude which are then pushed to the DSS for further processing.

2. Tide gauges along the Sunda Arc coasts which are used to give evidence of the arrival of a tsunami wave at the coast.

3. Buoys and ocean bottom pressure sensors which are used to detect wave anomalies in the marine region along the Sunda Arc. Their sampling frequency is reduced except when in "tsunami mode" in order to save battery energy. The DSS is used to automatically trigger tsunami mode as part of the DSS sensor tasking.

4. GPS sensors which are used to detect ground deformations using precise CPGS measurements. These can also be used to denote the seismic rupture's directivity (Babeyko et al., 2010). Precise GPS sensors are also attached to the buoys for sea level measurements.

5. Tsunami Simulation Scenarios: several thousands of scenarios are pre-computed using the TsunAWI model from Alfred-Wegener-Institute (AWI) for an array of locations along the possible rupture zone of the Sunda Arc for different earthquake magnitudes from Magnitude 7.5 to 9.0 and stored in a database from which the DSS can extract relevant data within seconds. A simulation system (AWI SIM) provides online scenario matching capabilities to the DSS by which observed physical quantities are used to compare with the same physical quantities' values in pre-modelled wave propagation scencarios (Behrens et al., 2010) primarily according to location. To be prepared to use the pre-calculated scenarios online, both the simulation system and the 


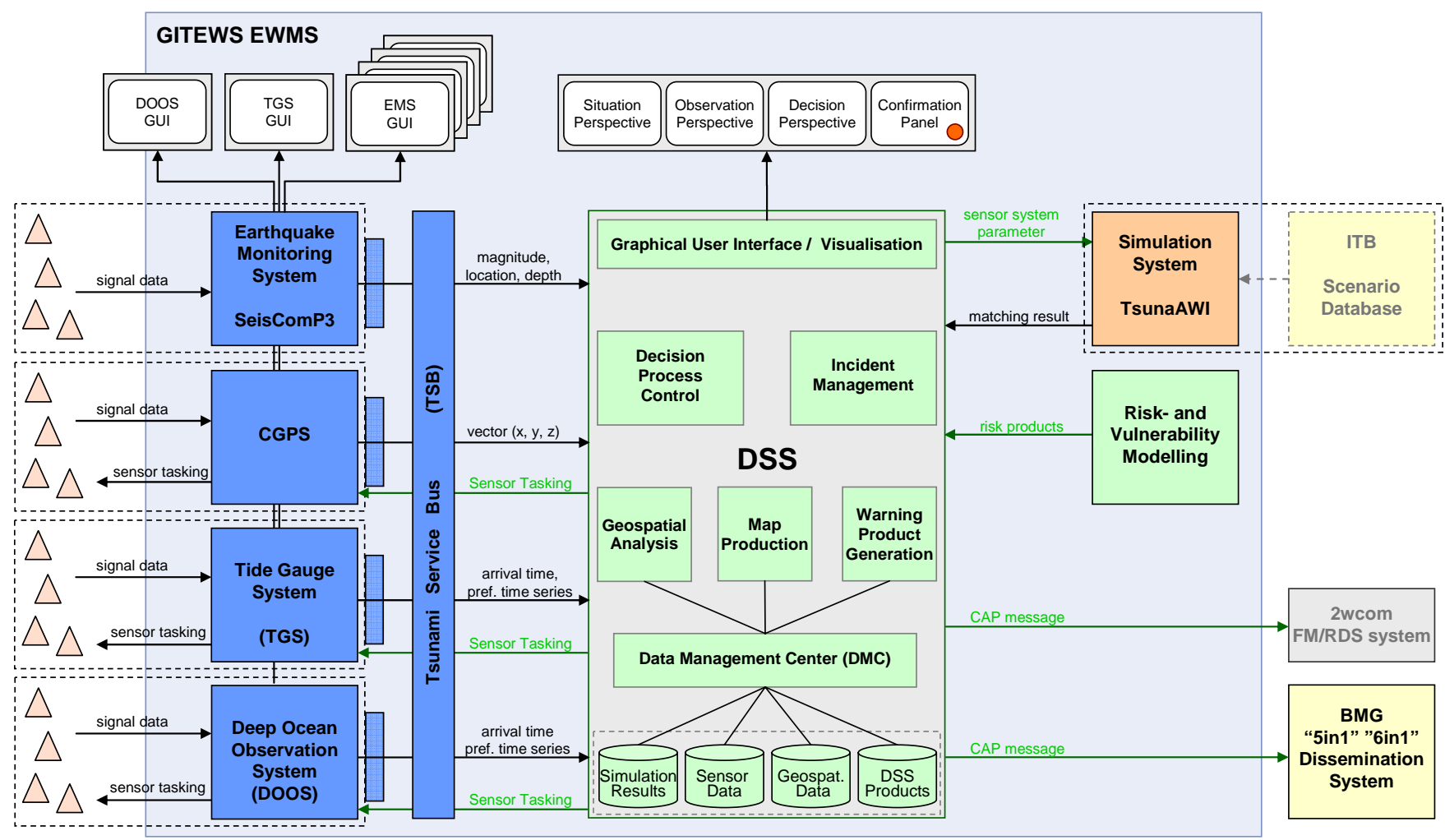

Fig. 1. The architectural view of the Early Warning and Mitigation System (EWMS). Bright box in the center: DSS Data Management Center. Above it: DSS Graphical User Interface (aka: DSS Client).

DSS need to pre-process key data relevant for the early warning process in advance. This offline process involves statistical data mining and is called "ingestion".

\subsection{Architectural view}

The Decision Support System itself is a combination of a server component, comprised of databases and repositories into which the external sensor systems, internal geodatabases and the simulation matching system feed their data, as well as a client part (GUI), which is used to visualize the information and configure the decision support information. These components and their interconnections to the other GITEWS Early Warning and Mitigation System (EWMS) components can be seen in Fig. 1. All hardware and software components use a high-availability setup to fulfill $24 / 7$ requirements, including a training facility which can be used independently of the operational system.

The central part of the DSS server component is the Data Management Center which comprises the base geodata repositories as well as pre-computed, pre-extracted scenario data and it is also the location where the incoming data from the other sensor systems is stored in an ingestion process. These databases can then be used in the simulation matching process to make the comparison with the pre-computed sensor data.
The aforementioned sensor systems, including the simulation system, as well as the dissemination system are external systems which are connected to the DSS using services based on the Open Geospatial Consortium (OGC) sensor web enablement (SWE) specifications (Botts et al., 2006; Raape et al., 2010). The OGC initiative for sensor web enablement aims at defining standards to enable the discovery, exchange and processing of sensor observations, as well as the tasking of sensor systems (Botts and Robin, 2010; Cox, 2006). Namely these services are sensor observation service (SOS), (Na and Priest, 2006), sensor alert service (SAS), Sensor Planning Service (SPS), (Simonis, 2005), web map service (WMS), web feature service (WFS), web processing service (WPS), and other industry standards, like the common alerting protocol (CAP, OASIS, 2001). The data flow is accomplished in an enterprise service bus (ESB) architecture, the "tsunami service bus" (Fleischer et al., 2010). The use of these standards is an investment into the system's future in that it makes the sensor system architecture easily extensible. Future systems that adhere to these standards can be used to extend the DSS's capabilities.

Whereas all of these systems comprise at least some level of analysis software or even a graphical user interface, none of them delivers more than what is considered enhanced tsunami detection input data to the DSS. It is then up to the DSS to combine all of these measurements and use 
an inversion solution to come to a tsunami early warning decision proposal. Extending the formerly used "one-way" communication from sensors to receiving analysis systems, the DSS uses intelligent sensor tasking based on SWE services in order to switch sensors from "idle mode" into "tsunami mode" (and back) when initial signs for an event are detected or an incident is decided to be cancelled. In "tsunami mode" the sampling frequency is increased from the (battery and bandwidth saving) idle mode thus enabling the DSS to receive better information faster while putting the lowest stress on the sensors' energy supply. The DSS sensor tasking decides which and when sensors to switch into/out of "tsunami mode" for each potential tsunami case individually, based on a spatio-temporal ruleset. This process of sensor tasking is performed automatically and provides an extremely fast activation of relevant sensors.

Additional data stored in DSS databases deal with models for the vulnerability posed to each part/administrative area of the coast. These are pre-computed using large amounts of socio-economic data. Using combinations of deterministic and probabilistic statistical models with which the hazard for these areas is simulated, the risk which arises to each of these administrative areas have been computed. The COOD has access to these detailed risk and vulnerability databases in the DSS to support him in his decision making. The data are not, however, used directly in the decision finding process of DSS yet.

\subsection{Data flow during an event}

While the DSS will in most cases be mainly triggered using the input from the Seismic analysis system, SeisComp3, it can, however, be triggered by the other sensor systems, if those transmit their data first. When sensor data arrive at the DSS the simulation matching system (SIM) is queried in order to find simulation scenarios which match all of the existing observations simultaneously and, if those can be found, matching scenarios are returned by the SIM.

If no suitable pre-computed scenario can be found, e.g. for EQ events outside the area of simulation coverage, other workflows are triggered which first check for the location of an earthquake on land or offshore and, depending on that, apply rules $\left(\mathrm{PTWC}^{1}\right)$ to denote the potential of the event to generate a tsunami. For magnitudes lower than 7.0 in the area of simulation coverage, it is assumed that no destructive tsunami will be generated. All incoming data dynamically trigger the SIM again and every result which depicts a different situational picture triggers updating of all related parts of the Graphical User Interface including map components, simulation graphics and tables on all four screens. As the GUI is continuously updated, the generation of a warning configuration and warning messages, is, accord-

\footnotetext{
${ }^{1}$ PTWC: Pacific Tsunami Warning Center, http://www.prh.noaa. gov/ptwc/, last access: 2010).
}

ingly, dynamically adapted. The COOD can interact with the GUI for the sensor tasking (increased/reduced sampling) and for adjusting warnings manually as well as creating and disseminating warnings through the attached dissemination systems.

\section{The decision support system}

As part of the Early Warning and Mitigation System, the DSS provides processing, assessment, visualization, decision support, analysis, warning and management functions for the purpose of supporting disaster management related activities regarding tsunami threats for the region of Indonesia.

\subsection{Operational prerequisites}

In order to be able to make a spatially differentiated warning it is necessary that the operator of the DSS use a segmentation of the coastline into smaller parts. Therefore the areas of coastal stretches used in the DSS have been chosen as managable parts along the coast using mostly administrative boundaries on the sub-district level. These parts are called Warning Segments (WS) and are the smallest warnable units in the warning dissemination process for which tsunami threat is aggregated and to which a warning can be addressed. The coastline of Sumatra, Java and Bali along the Sunda Arc has therefore been segmented into 125 warning segments using administrative areas. The remaining coastline of Indonesia currently comprises 245 additional warning segments.

During the Ingestion Process relevant data are extracted and aggregated from pre-calculated scenarios. Technically, a newly computed scenario has to be registered with the simulation system. After notification of the DSS Data Management Center, the ingestion process is triggered for this scenario, during which an aggregation (to the warning segment spatial resolution) of estimated wave height and estimated time of arrival is done. For all forecast points (point of interest, POI) along the coast in one warning segment, the median ETA and EWH are thus computed and stored in the Data Management Center as key values for the scenario matching process for this particular warning segment and scenario.

In order to express the level of threat for a warning segment, the EWH at the coastline is used. The EWH is then mapped onto a four-level color-coded scale of warning levels for each of to the warning segments. The current definition of warning levels is shown in Table 1. Warning levels can be in one of the following four states: none, Advisory $(0.1 \mathrm{~m} \leq \mathrm{EWH}<0.5 \mathrm{~m})$, Warning $(0.5 \mathrm{~m} \leq \mathrm{EWH}<3.0 \mathrm{~m})$, Major Warning $(3.0 \mathrm{~m} \leq \mathrm{EWH})$. Because the warning levels also imply the measures taken in the warning segments (e.g. evacuation), the thresholds are currently subject to further research in order to better align with "last-mile" activities. Options exist to also include other parameters into the calculation of appropriate warning levels. 
Table 1. Mapping of wave heights to Warning Levels.

\begin{tabular}{llll}
\hline $\begin{array}{l}\text { Tsunami } \\
\text { Category }\end{array}$ & $\begin{array}{l}\text { Warning } \\
\text { Level }\end{array}$ & $\begin{array}{l}\text { Wave Height } \\
(\mathrm{WH}) \text { Range } \\
{[\mathrm{m}]}\end{array}$ & $\begin{array}{l}\text { Color } \\
\text { Code }\end{array}$ \\
\hline$<$ none $>$ & $<$ none $>$ & $0.0 \leq \mathrm{WH}<0.1$ & Grey \\
Minor Tsunami & Advisory & $0.1 \leq \mathrm{WH}<0.5$ & Yellow \\
$\begin{array}{l}\text { Tsunami } \\
\text { Major }\end{array}$ & Warning & $0.5 \leq \mathrm{WH}<3.0$ & Orange \\
Tsunami & Major & $3.0 \leq \mathrm{WH}$ & Red \\
\hline
\end{tabular}

\subsection{Core decision support process}

The decision process shall help the COOD to be aware of a current situation, assess incoming information, exploit synergies of information fusion and analysis, assess impact and consequences and make informed decisions.

On an abstract level, the DSS has two main tasks:

1. To support the COOD in improving his situational awareness.

2. To support the COOD in taking a decision and eventually sending a warning.

This is the DSS Core Process which is continuously executed and iterated each time new information arrives at the DSS. Figure 2 shows the DSS Core Process in a schematic way:

- Level 1: Perception (gather and assess each single information).

- Level 2: Comprehension (assess and relate with other information).

- Level 3: Projection (estimate effects/project consequences).

In order to improve the situational awareness of the decision maker, the system has to support the COOD on the three subsequent levels of Perception, Comprehension and Projection before he will be able to decide and act given a DSS warning configuration for the event at hand. The DSS gives him this support by using information aggregation for which it uses information fusion techniques in turn to simplify access to otherwise too much information.

Information Fusion is commonly defined as the merging of information from disparate sources with differing conceptual, contextual and typographical representations. As one well-known subtype of Information Fusion, sensor fusion combines sensor data or data derived from sensor data from disparate sources such that the resulting information is in some sense better than it would be possible if these sources were used individually. The term better in that case can mean more accurate, more complete, or more dependable, or

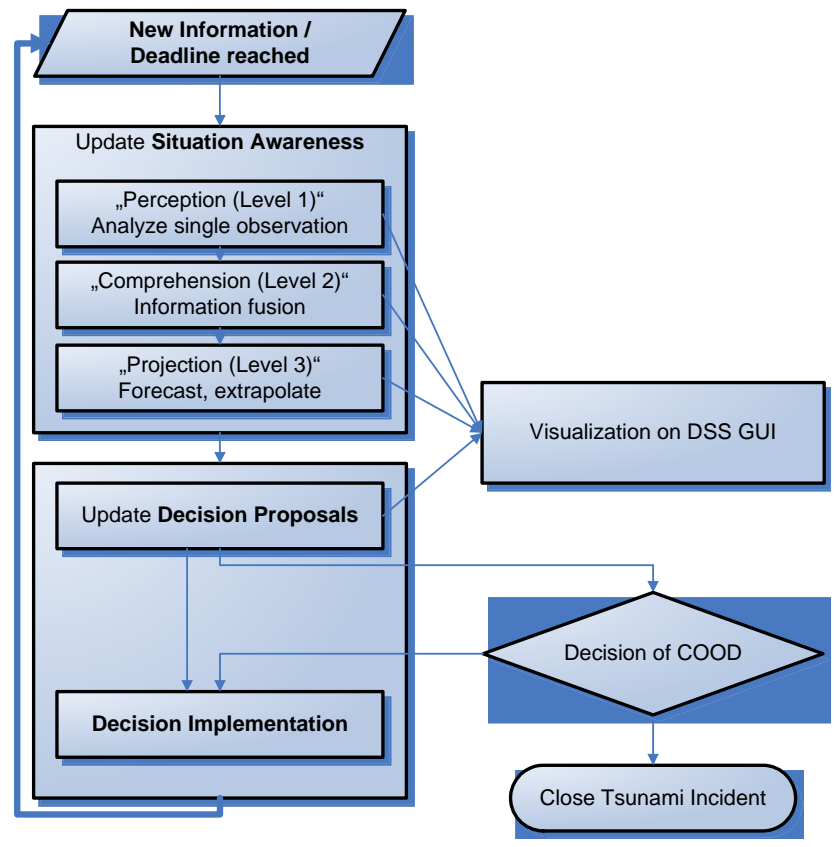

Fig. 2. The Decision Support Core Process. In Improving Situational Awareness, the system has to support the operator on the three subsequent levels of Perception, Comprehension and Projection before he will be able to decide and act given a warning configuration for the event at hand. The cycle is repeated every time new information becomes available.

refer to the result of an emerging view. One can distinguish direct fusion, indirect fusion and fusion of the outputs of the former two. Direct fusion is the fusion of sensor data from a set of heterogeneous or homogeneous sensors, soft sensors, and history values of sensor data, while indirect fusion uses information sources like a priori knowledge about the environment and human input (Blasch, 2005; Steinberg et al., 1998).

The SIM uses heterogeneous sensor observations simultaneously to select the best matching tsunami scenarios and thus may be considered to use sensor fusion. From the DSS' point of view the SIM provides one of several real-time inputs for the overall information fusion process that is performed by the DSS. Hence the fusion process includes not only direct sensor fusion of data delivered by the heterogeneous sensor and simulation infrastructure but also indirect fusion techniques including a priori knowledge (e.g. geographic baseline data, risk and vulnerability analysis, pre-computed tsunami scenario parameters) stored in the DSS.

The aggregated information which the COOD can visualize on the DSS client graphical user interface (GUI) helps him first in perceiving, then comprehending and finally in accepting (or refusing/modifying) the warning configuration which is computed by the DSS by using a projection of what is currently happening to what will happen in the near future. The system is able to provide the user 
with detailed projections by means of simulated scenarios, from which information like the estimated times of arrival and the estimated wave heights are taken. The COOD should be able to make a decision at every time based on the information obtained in one core decision support process cycle. While situational awareness refers to understanding the currently ongoing incident, this understanding needs to be used to derive actions. Therefore, the second part of the decision support loop comprises the decision as to what warning message to create for what warning segment and the action to send this warning or not. The process is repeated iteratively making the DSS react dynamically to changes of the data occurring in time or space until no more tsunami threat exists.

\subsection{Interaction with the simulation system}

The DSS contains pre-compiled databases on the run-up and inundation effect of each of the pre-computed scenarios for a large number of points of interest (POI) along the coast (approx. distance between points $500 \mathrm{~m}$ ). To compile these databases, an offline "ingestion" process is used to extract data relevant to the tsunami early warning process from the repository of available tsunami simulation scenarios generated by the TsunAWI simulation model. The effect on each warning segment is pre-aggregated for each scenario, for every warning segment. The DSS triggers the simulation matching process again using all current observations every time when new observation data are obtained by any of the external sensor systems (Behrens et al., 2008). As part of the DSS/SIM interaction, the SIM provides a weighted list of best-matching scenarios to the DSS, along with additional quality and error measures (see Behrens et al., 2010). At this step the DSS must decide which tsunami scenario description should be used for the remaining situational awareness and decision support process.

The DSS can be configured to use one of the two following behaviours: the "straightforward" approach is to just select the best scenario in the list (the so-called "best-fit" approach). Due to the inherent uncertainty at this early point of the warning process, the risk of choosing a sub-optimal scenario is quite high. Therefore, the DSS offers a second approach called "scenario aggregation": the DSS decides, based on the length of the SIM result list as well as the scenarios listed and the accompanying quality and error measures, how many and what scenarios to aggregate in order to generate a "preferred scenario". Usually, the scenarios are aggregated using a worst-case approach (Fig. 5).

\subsection{Information fusion and workflow in the graphical user interface}

Command and control systems tend to be overloaded with information if the amount of information to be used by a COOD is large. It is therefore inherently difficult to find the

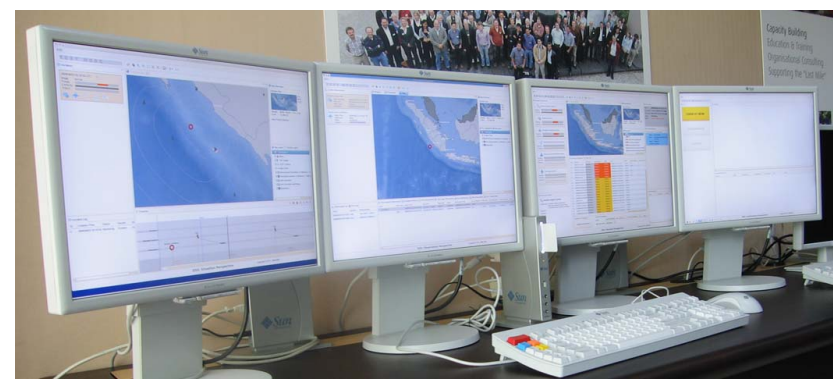

Fig. 3. The four screens (aka: Situation Perspective, Observation Perspective, Decision Perspective and Product/Dissemination Perspective) on a training workplace in the Warning Centre of BMKG in Jakarta.

right trade-off between the required amount of information content to make a well informed decision and the point from which on the operator is distracted from his main task - to take the right decision to warn. The GITEWS DSS strives to make the interface as easy as possible to understand and interact with while maintaining a high level of information from the array of sensor and simulation systems whose data it consumes.

Since the Graphical User Interface (GUI) of the DSS is most prominent to the user of the DSS and because it is the one part which is used to trigger interaction with the DSS server component, a short introduction to the GUI is given: the DSS uses a setup of four screens which are positioned side by side to provide all levels of information to the operator in the different stages of the decision process. Figure 3 shows the four screens of the DSS in the context of a training workplace in the warning centre at BMKG in Jakarta.

The multi screen setup was chosen such as not to overwhelm (and potentially distract) the COOD with information he would not normally want to see. He can hence use the screens sequentially from left to right, where the sequence corresponds to the aforementioned sequence of Perception, Comprehension, Projection, Decision and Action. Given the fact that he has to work with information selectively to arrive at the overall result within the short time frame after an earthquake, information visualisation must be chosen carefully, reducing information overload. Such a setup can be used for decision making even under uncertainty and time pressure (Endsley et al., 2003).

A large amount of work has gone into the ergonomics and usability considerations for the DSS. Eye tracking studies have been conducted on a previous version of the GUI to ensure that important information is in places on the screen where the operator can find it quickly (FH Potsdam Interaction Design, 2007) resulting in the improved current layout. 


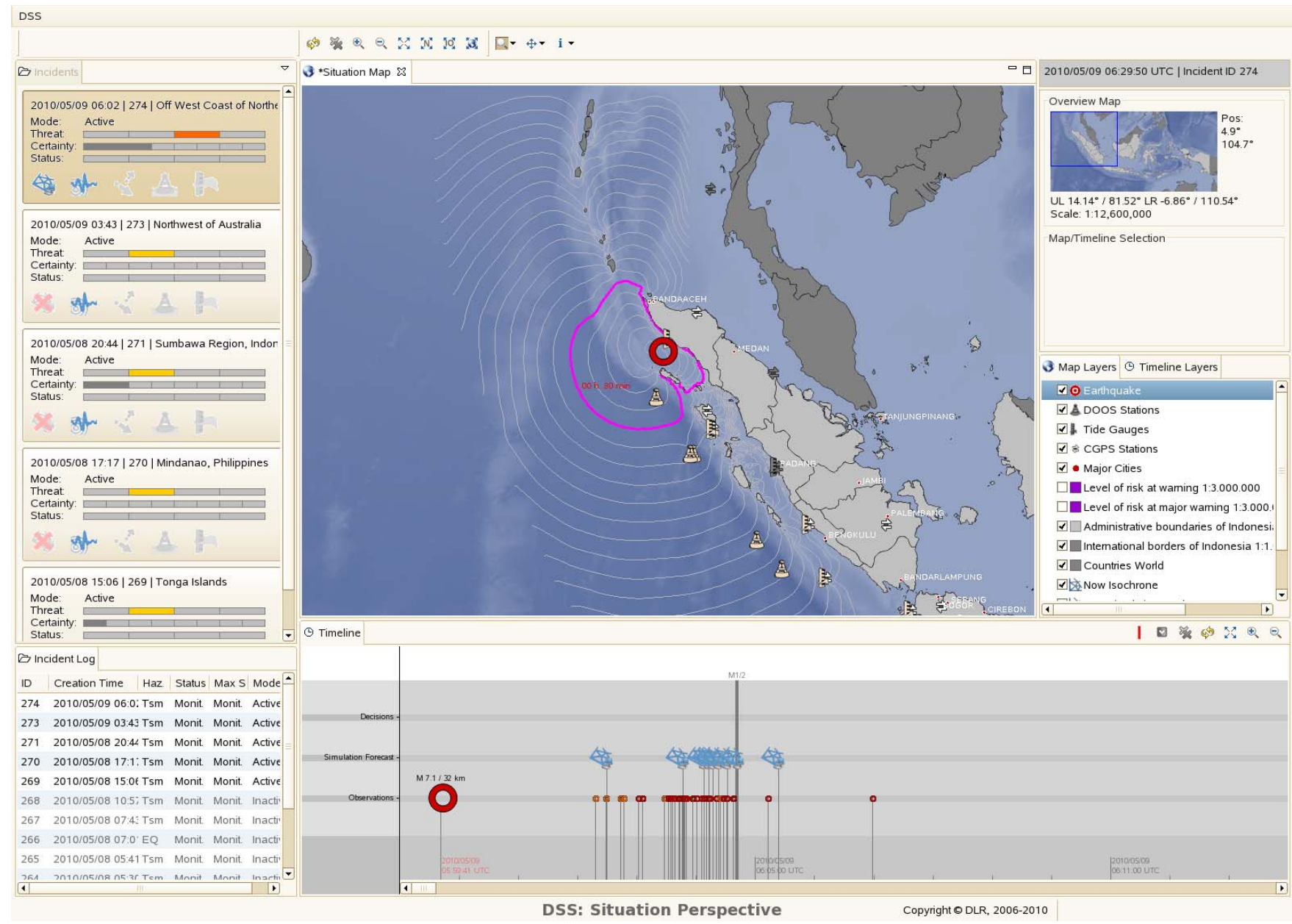

Fig. 4. Situation Perspective (overview of the situational picture). The map shows wave propagation isochrones with the EQ location shown as a red circle inside them. The operator can chose among all "incidents", in order to display all data relevant to that incident. Each incident contains the aggregated information about its individual threat, certainty and status. A timeline on the bottom depicts the situational picture as it evolves in the course of time (which sensor observation is expected to be received next, which coastal warning segment is expected to be hit at what time etc.).

The four screens (and their corresponding task in the decision process) are named as follows:

- Situation Perspective (Comprehension)

- Observation Perspective (Comprehension/Projection)

- Decision Perspective (Projection/Action)

- Product/Disseminaton Perspective (Action)

The Situation Perspective (Fig. 4) is used by the operator to gain a quick high-level overview of the situation using colored symbols for all relevant facts of interest (observations, simulation forecasts, sensor system location and stati) on a map and a timeline. Information belonging to one earthquake event is collected in a so called incident in the DSS internally, which is symbolized by an incident strip in the DSS GUI. Incidents strips which appear on the left side of the situation perspective can be used to switch back and forth between the data and visualizations of separate incidents by selecting one of them. The incident concept used here, which is able to group data belonging to dozens of individual events (like they occur e.g. as a result of afterquakes in the time following large earthquake events), is one more novel approach not currently used by any other tsunami early warning system. It enables the COOD to neatly distinguish between data - and therefore: consequences - that are collected in conjunction with separate events. An incident stays open until the COOD closes it, meaning the collection of incoming data from the sensor systems can continue for several incidents in parallel while keeping assessments and visualizations as well as decision proposals and the COOD's decisions apart from each other in the GUI. 


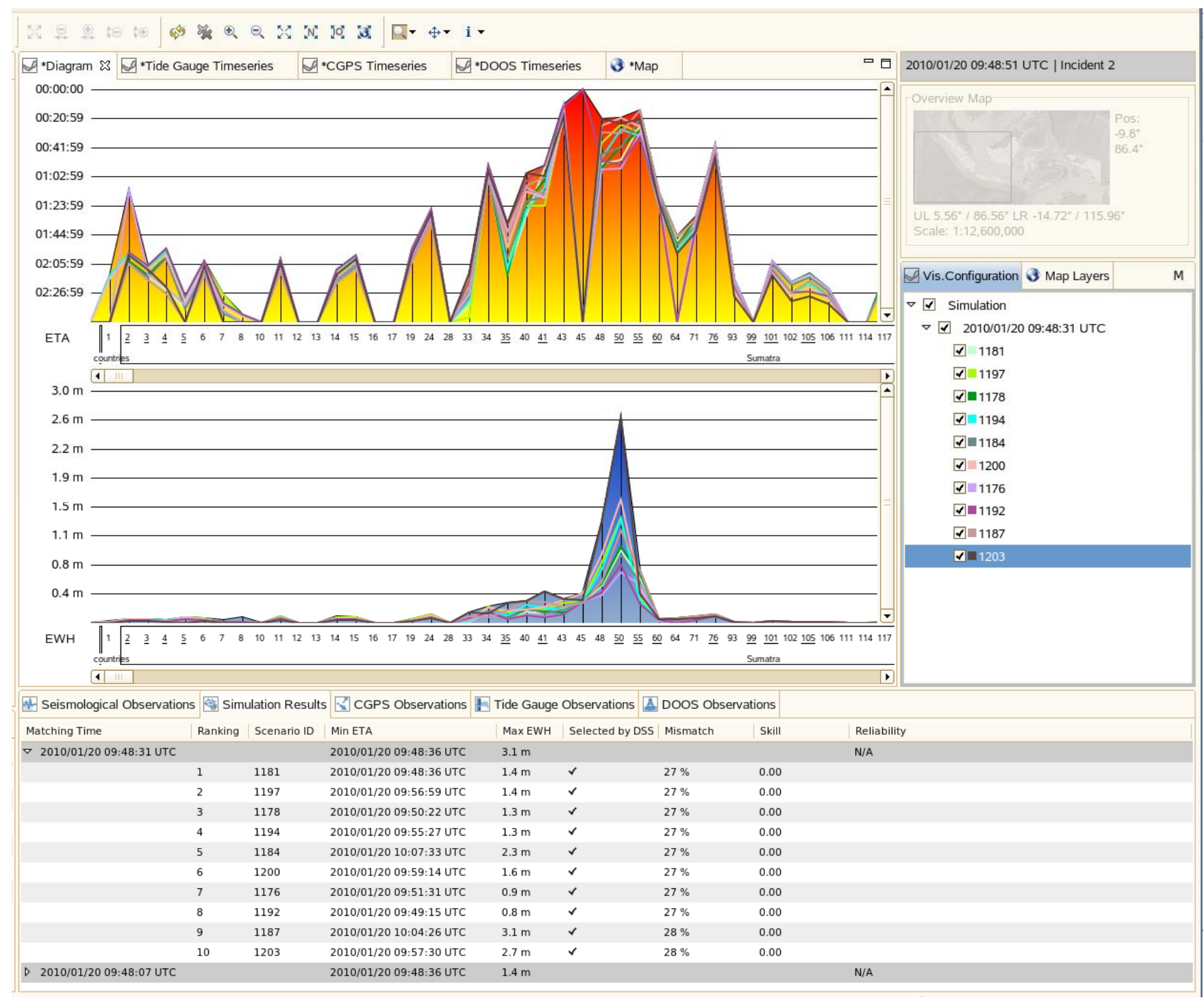

Fig. 5. Simulation Visualization Diagram in the Observation Perspective, showing Scenario Aggregation. Each curve represents ETA (estimated time of arrival) on the top diagram and EWH (estimated wave height) on the bottom diagram, respectively, for a single scenario along the coast (each number along the horizontal axis represents one coastal warning segment. The black curve shows the aggregated worst case for all scenarios selected in the simulation matching process for one set of observations.

The Observation Perspective (Fig. 5) provides space for all the observation data that can be analyzed by the COOD. Clickable tabs on the top part of the screen provide access to sensor and simulation related information using either maps, a simulation visualization for estimated wave heights or estimated times of arrivals at differentiated parts of the coast, and corresponding in the bottom part of the screen. This provides the user with quick looks on all the relevant observation and simulation data, separately.

Once the DSS has gone through the decision support loop for the first time and the COOD wants to use the DSS decision support, he can find the warning configuration on the Decision Perspective (third screen, Fig. 6) to that aim, which contains detailed information about the warning levels in different coastal parts according the simulation results. If warning levels for individual warning segments are not available for events originating outside of the area of simulation coverage, they are assigned according to internal rules of the DSS. The decision perspective is also the place where the operator sees detailed risk and vulnerability information (Fig. 5) related to individual warning segments. This is a feature unique to the GITEWS DSS. Whereas such information is not used in the generation of a decision proposal, the COOD is free to use it as background information to base his own (human) decision upon. As a general rule, the COOD always has the opportunity to override the automatic warning configuration. 


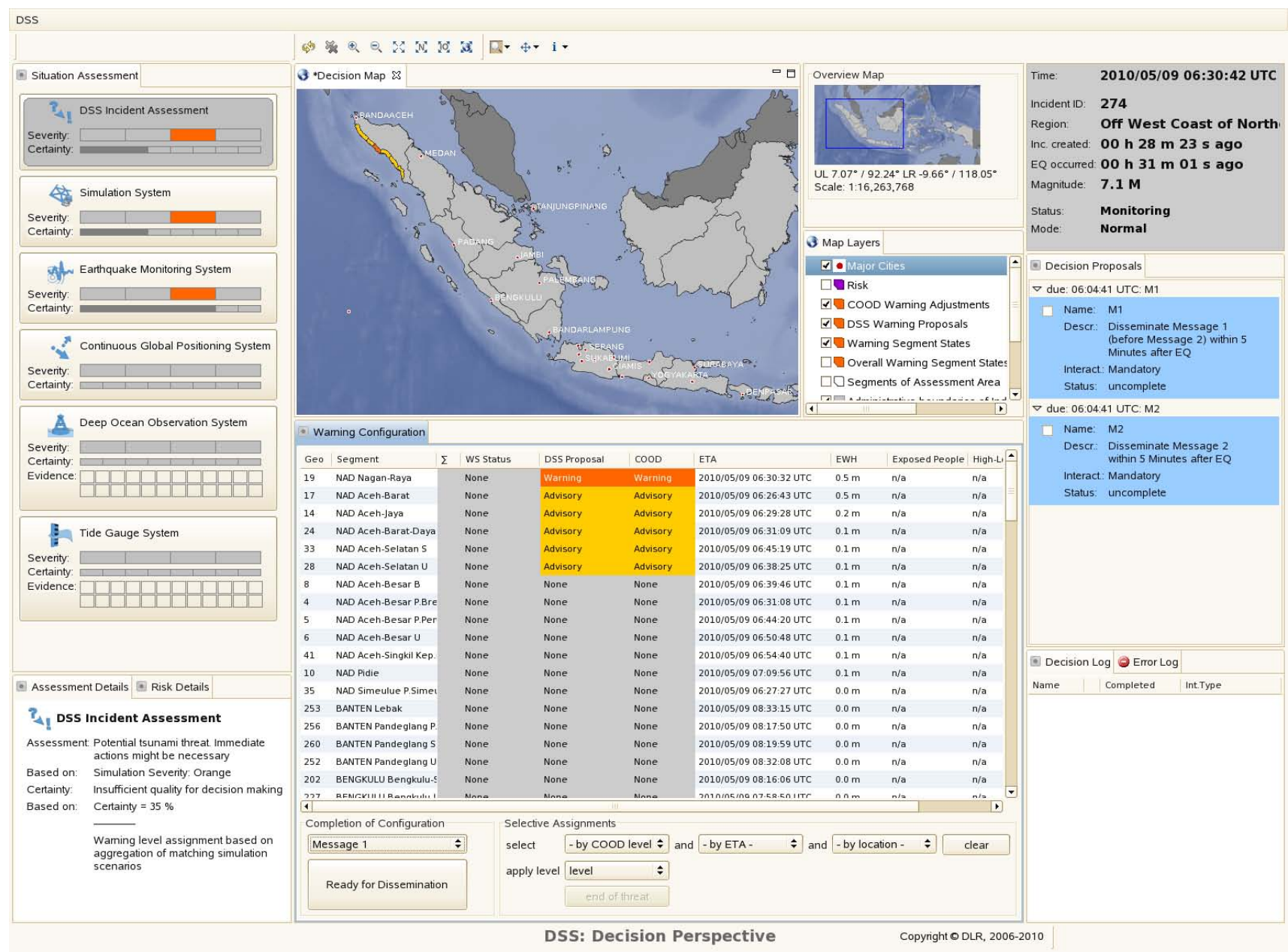

Fig. 6. Integration of Risk and Vulnerability Information in the Decision Perspective. The map shows the individual risk and the table lists numbers for "exposed people" and "high-loss infrastructure" for each affected warning segment. Each warning segment in the list is additionally color coded for the warning level and the overall risk.

Once the COOD is satisfied with the warning configuration he can simply click a button to trigger the creation of messages which can then be reviewed and finally sent to external dissemination systems using the dissemination/ product perspective (fourth screen). The DSS provides an open interface to dissemination systems connectable to it by providing multi-language, multi-format, templated warning messages. Currently the DSS connects to BMKG's proprietary automatic dissemination system which is used to send short messages using SMS as well as long messages using FAX and email to subscribed recipients. Messages are also transmitted automatically to a web interface (BMKG homepage). Thus it is entirely in the scope of these external dissemination systems - which are under the maintainance and control of Indonesian institutions - to disseminate the generated messages.

\section{Operational experience}

The DSS system has now been in pre-operational use based on seismic data alone since April 2010. BMKG operators working 24/7 shifts have continuous access to the DSS's information in order to improve their situational awareness in every kind of seismic event. Since this time the system has proven its capability to support country wide tsunami early warning. A number of events of varying magnitudes large enough to trigger a decision recommendation from the system have occurred since then, most notably the following potentially tsunamigenic strong earthquakes:

- North Sumatra, M 7.6, 6 April 2010

- North Sumatra, M 7.1, 9 May 2010

- Vanuatu Islands, M 7.1, 27 May 2010

- Irian Jaya Region, M 7.4, 16 June 2010

- Solomon Islands, M 6.6, 26 June 2010 
Table 2. Sequence of events during the 6 April 2010 Sumatra earthquake incident.

\begin{tabular}{|c|c|c|c|}
\hline Description & $\begin{array}{l}\text { Time/ } \\
\text { time lag }\end{array}$ & $\begin{array}{l}\text { ETA/EWH } \\
\text { (estimation) }\end{array}$ & $\begin{array}{l}\text { OTA/OWH } \\
\text { (observation) }\end{array}$ \\
\hline EQ source time & $\begin{array}{l}6 \text { Apr } 2010 \\
22: 15: 03\end{array}$ & & \\
\hline SC3. First seismic observation to DSS & $+00: 02: 29$ & & \\
\hline SC3. First seismic observation to DSS with $M \geq 6.5$ (threshold) & $+00: 02: 38$ & & \\
\hline DSS: first SIM triggering (after first $M \geq 6.5$ ) & $+00: 02: 38$ & & \\
\hline DSS: first SIM result $(M$ x.x, EWH $)$ & $+00: 02: 40$ & $\operatorname{maxEWH}=0.4 \mathrm{~m}$ & - \\
\hline $\begin{array}{l}\text { DSS: first situation overview + decision proposals } \\
\text { (first option for COOD to disseminate DSS tsunami warnings) }\end{array}$ & $+00: 02: 41$ & & \\
\hline SC3. First seismic observation to DSS with $M \geq 7.5$ & $+00: 04: 34$ & & \\
\hline DSS: SIM triggering (after first $M \geq 7.5$ ) & $+00: 04: 35$ & & \\
\hline \multirow[t]{2}{*}{ DSS: updated SIM result ( $M$ x.x, EWH $)$} & $+00: 04: 36$ & $\begin{array}{l}\text { TG Meulaboh: } \\
\text { 23:07 UTC }(0.4 \mathrm{~m})\end{array}$ & $\begin{array}{l}\text { TG Meulaboh: } \\
\text { 23:20 UTC }(0.35 \mathrm{~m})\end{array}$ \\
\hline & & $\begin{array}{l}\text { TG Pulau Banyak: } \\
\text { 23:07 UTC }(0.4 \mathrm{~m})\end{array}$ & $\begin{array}{l}\text { TG Pulau Banyak: } \\
\text { 22:25 UTC }(0.35 \mathrm{~m})\end{array}$ \\
\hline $\begin{array}{l}\text { DSS: updated situation overview + decision proposals } \\
\text { (first solution "near" to the real situation) }\end{array}$ & $+00: 04: 39$ & & \\
\hline $\begin{array}{l}\text { Until } 6 \text { April } 2010 \text { 23:31:16 UTC DSS received } 50 \text { seismic observations } \\
\text { from SC3 for this earthquake and adapted its decision support continuously. }\end{array}$ & $(+01: 14)$ & & \\
\hline
\end{tabular}

System Performance can best be assessed or validated by investigation of these examples. For the event on 6 April 2010 the DSS generated a first situation overview and offered a decision proposal for the initial SeisComp3 reported magnitude $M 6.5$ only $2 \min 41 \mathrm{~s}$ after the EQ origin time. DSS then estimated the maximum wave height at the west coast of the province of Aceh to be $0.8 \mathrm{~m}$ about $2 \mathrm{~min}$ later, which was $5 \mathrm{~s}$ after it had first received the increased magnitude $M 7.5$ (which exceeds the threshold magnitude $M 7.0$ which is required to trigger the DSS tsunami workflow) from the seismic system.

Observations from a tide gauge at Pulau Banyak, an island west of the province of Aceh, indicate a maximum increase in sea level of $0.45 \mathrm{~m}$ from that event. The estimated time of arrival at the warning segment indicated to be hit first matches very well with the observed point in time where the sea level increased at the Pulau Banyak tide gauge as well as at the Meulaboh tide gauge (see Table 2 for the sequence of DSS events).

This provides only a rather rough validation result but is an encouraging result with respect to to the efforts of finetuning the system parameters. Generally system behaviour so far has been exactly as expected and the performance in terms of providing timely information has shown to exceed formal requirements.

Similarly successful results have been achieved for the other events where simulated scenarios are available.

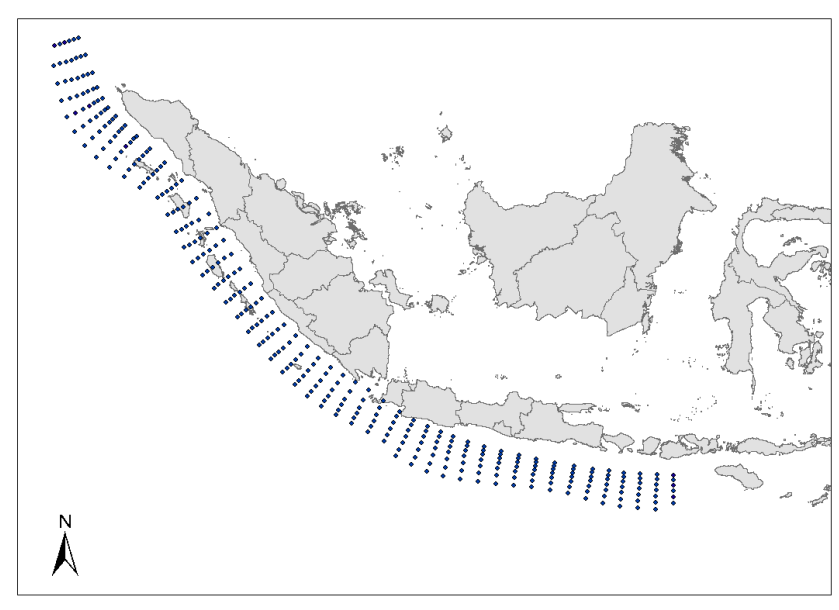

Fig. 7. Area of simulation coverage with AWI scenarios.

A warning has not necessarily been disseminated for each of these events, but the DSS always generates an assessment of the situation and a recommendation as to what action to take. For areas outside the area of simulation coverage, i.e. EQ locations for which there are no pre-calculated scenarios, the assessment and decision support given is done with a rule base - considering PTWC (pacific tsunami warning center) rules which are currently undergoing a revision in order to make them applicable for the particular situation in Indonesia. 


\section{Next steps}

The UNESCO Intergovernmental Coordination Group for the Indian Ocean Tsunami Early Warning System (ICGIOTWS) has specified requirements for warning and information products to be delivered by so-called Regional Tsunami Watch Providers (RTWP). Until now Australia, India and Indonesia have officially indicated to take over the role of a RTWP for the Indian Ocean. The GITEWS Decision Support System is prepared to provide regional tsunami watch messages following these specifications (UNESCO, 2008). However, additional work has to be done to enable the system to use its full capabilities of information fusion and aggregation for the whole Indian Ocean, i.e. extensions of the geodatabase, extension of the scenario data base for simulations (including inundation) covering the whole Indian Ocean Basin (the simulations contained in the data base are actually calculated for $3 \mathrm{~h}$ tsunami travel time which is sufficient for national warning purposes) and to include the Makran source region.

Furthermore the simulation data base has to be extended to the northern and north-eastern coastlines of Indonesia (see Fig. 7 for the current area for which simulations have been computed within the GITEWS project). In this context additional scenarios shall be integrated, e.g. scenarios which have been computed in Indonesia at ITB (Institut Teknologi Bandung) (Hadihardaja et al., 2010).

A Risk Perspective on an additional display is planned to extend the operators' capabilities to work with the "raw" socioeconomic data and to update risk and vulnerability information. This perspective can also be used in the desaster response and recovery phase, as well as in the early warning. In order to stick with the philosophy of not distracting the COOD by showing too much information in a single screen, a fifth screen shall be used for the risk perspective.

\section{Conclusions}

Nearfield Tsunami Early Warning like in Sumatra, Java, and Bali is a particularly difficult task due to the short warning times. The ability of a warning to reach people has - until the recent achieval of the building up of such structures after the Boxing Day Tsunami 2004 - largely been hindered by a lack of dedicated communication infrastructures, of established authorities and operational procedures for the warning dissemination. Therefore decision support not only has to deal with a high uncertainty due to the inherent lack of sufficient data in the first minutes and technical difficulties, but also with culturally and hierarchically implied pressure which is put on the decision maker. Many improvements have been achieved in the course of the GITEWS project concerning the technical and communication infrastructure as well as what mechanisms and standard operation procedures to use for the warning dissemination. In the future these improvements will have to be measured in conjunction with BMKGs new possibilities to react to an event in time. The decision support system presented in this paper forms a central node in the complete upstream/downstream warning chain. It aggregates upstream information and triggers the downstream part, where the national warning provider at the BMKG operation center in Jakarta constitutes the upstream part, whereas the downstream part - extending to the people at risk at the far end of the warning chain - is made up of the different external dissemination systems. GITEWS was designed with both ends in mind. Therefore, the system provides risk and vulnerability information, among others, in highly aggregated displays (Fig. 3). This is one of the not quite visible, yet innovative, approaches which make the system stand out from traditionally used systems. This DSS strives to improve those by mapping warning levels to inundation areas at the coast shown in the DSS decision proposals and by providing the warnings mentioning the respective reaction scheme for evacuation (Spahn et al., 2010). Thus, in conjunction with local administrations' trainings to improve the receiving, understanding and interpretation of the tsunami warning, GITEWS DSS is able to generate situational awareness faster at both ends of the warning chain, thereby improving people's ability to understand, react and escape.

The system uses novel sensor systems which can be extended in a modular way. Decision making follows well-known approaches where required (adapted PTWC distance-/magnitude-based assessment rules for areas outside of the area of simulation coverage; PTWC, 2010) and innovative assessments where more detailed information is available (inside the area of simulation coverage along the Sunda Arc, Fig. 7).

Using a set of filters the system is able to focus on relevant events and observations early enough to improve the system's responsiveness and keep irrelevant data away from the operator who is required to take difficult decisions with a high responsibility under heavy time pressure. Using, among others, incident data collection and other unique visualization and analysis approaches, information content is highly aggregated in the Graphical User Interface, such that a single operator can make well informed decisions without having to struggle with dangerous "information underflow/overflow" phenomena, but it still leaves him the possibility to scrutinize all relevant information and, if desired, override the system's decision proposals.

Extension paths, in the technical respect for DSS and sensor systems alike, as well as concerning international cooperation in the RTWP context, are numerous and will hopefully ensure a stable base for many years of successful usage of the system.

Acknowledgements. The GITEWS project (German Indonesian Tsunami Early Warning System) is being developed by a number of scientists and engineers of the Helmholtz Centre Potsdam GFZ German Research Centre for Geosciences (GFZ, Project Lead), the 
Alfred Wegener Institute for Polar and Marine Research (AWI), the German Aerospace Center (DLR), the GKSS Research Centre (GKSS), the German Marine Research Consortium (KDM), the Leibniz Institute of Marine Sciences (IFM-GEOMAR), the United Nations University Institute for Environment and Human Security (UNU), the Gesellschaft für Technische Zusammenarbeit (GTZ) and the Federal Institute for Geosciences and Natural Resources (BGR) as well as Indonesian and international partners. The project is funded by the German Federal Ministry for Education and Research (BMBF), Grant 03TSU01.

Edited by: J. Lauterjung

Reviewed by: two anonymous referees

\section{References}

Babeyko, A. Y., Hoechner, A., and Sobolev, S. V.: Source modeling and inversion with near real-time GPS: a GITEWS perspective for Indonesia, Nat. Hazards Earth Syst. Sci., 10, 1617-1627, doi:10.5194/nhess-10-1617-2010, 2010.

Behrens, J., Androsov, A., Babeyko, A. Y., Harig, S., Klaschka, F., and Mentrup, L.: A new multi-sensor approach to simulation assisted tsunami early warning, Nat. Hazards Earth Syst. Sci., 10, 1085-1100, doi:10.5194/nhess-10-1085-2010, 2010.

Behrens, J., Androsov, A., Harig, S., Klaschka, F., Mentrup, L., and Pranowo, W. S.: A New Multi-Sensor Inversion Approach for Fast and Reliable Near-Field Tsunami Early Warning, Proceedings of the International Conference on Tsunami Warning (ICTW), Bali, Indonesia, 2008.

Blasch, E.: Information Fusion for Decision Making, in: Data Fusion for Situation Monitoring, Incident Detection, Alert and Response Management, edited by: Shahbazian, E., Rogova, G., Valin, P., et al., IOS Press, 2005.

Botts, M., Percivall, G., Reed, C., and Davidson, J.: "OGC ${ }^{\circledR}$ Sensor Web Enablement: Overview and High Level Architecture", 2006.

Botts, M. and Robin, A. (Eds.): OpenGIS Sensor Model Language (SensorML) Implementation Specification Standard 1.0, available at: http://www.opengeospatial.org/standards/sensorml, OpenGIS document 07-000 SensorML available at: http://portal. opengeospatial.org/files/?artifact_id=21273, last access: $31 \mathrm{Au}-$ gust 2010 .

Cox, S.: OGC ${ }^{\circledR}$ Observations and Measurements Abstract Specification, available at: http://www.opengeospatial.org/standards/ om (last access: 31 August 2010), 2006

Part 1 - Observation schema, Document \# 07-022r1,

Part 2 - Sampling Features (1.0), Document \# 07-002r3.

Endsley, M. R. and Bolté, B., and Jones, D. G.: Designing for Situation Awareness, Taylor and Francis, Boca Raton, 2003.

FH Potsdam Interaction Design - Eyetracking Analysis: Usability Research Study of the German-Indonesian Tsunami Early Warning System (GITEWS), available at: http://design.fh-potsdam. de/fachbereich/transfer/kooperationen.html (last access: $31 \mathrm{Au}-$ gust 2010), 2007

Fleischer, J., Häner, R., Herrnkind, S., Kloth, A., Kriegel, U., Schwarting, H., and Wächter, J.: An integration platform for heterogeneous sensor systems in GITEWS - Tsunami Service Bus, Nat. Hazards Earth Syst. Sci., 10, 1239-1252, doi:10.5194/nhess-10-1239-2010, 2010.
FM-RDS 2wCOM: http://www.2wcom.com, last access: 31 August 2010.

Hadihardaja, I. K., Latief, H., and Mulia, I. E.: Decision support system for predicting tsunami characteristics along coastline areas based on database modelling development, J. Hydroinform., in press, doi:10.2166/hydro.2010.001, 2010.

Incident: The CAP Cookbook, available at: http://www.incident. com/cook-book/index.php/Creating_CAP_Applications (last access: 31 August 2010), 2008.

Lauterjung, J., Münch, U., and Rudloff, A.: The challenge of installing a tsunami early warning system in the vicinity of the Sunda Arc, Indonesia, Nat. Hazards Earth Syst. Sci., 10, 641646, doi:10.5194/nhess-10-641-2010, 2010.

Na, A. and Priest, M.: OGC ${ }^{\circledR}$ Sensor Observation Service Implementation Specification Sensor Observation Service 1.0, OpenGIS Sensor Observation Service, Document \#06-009r6, available at: http://www.opengeospatial.org/standards/sos (last access: 31 August 2010), 2007.

OASIS: Common Alerting Protocol, v.1.1, Oasis Standard CAPV1.1 Online Resource, available at: http://www.oasis-open.org/committees/download.php/15135/ emergency-CAPv1.1-Corrected_DOM.pdf (last access: 31 August 2010), October 2005.

Raape, U., Teßmann, S., Wytzisk, A., Steinmetz, T., Wnuk, M., Hunold, M., Strobl, C., Stasch, C., Walkowski, A. C., Meyer, O., and Jirka, S.: Decision Support for Tsunami Early Warning in Indonesia: The Role of OGC Standards, in: Lecture Notes in Geoinformation and Cartography, in: Geographic Information and Cartography For Risk and Crisis Management: Towards Better Solutions, 1st edn., edited by: Konecny, M., Zlatanova, S., and Bandrova, T. L., Springer, London, ISBN:978-3-642-034411, 400 pp., 2010

Rudloff, A., Lauterjung, J., Münch, U., and Tinti, S.: Preface "The GITEWS Project (German-Indonesian Tsunami Early Warning System)", Nat. Hazards Earth Syst. Sci., 9, 1381-1382, doi:10.5194/nhess-9-1381-2009, 2009.

Simonis, I.: Sensor Planning Service, OpenGIS Sensor Planning Service Implementation Specification, Document \#07-014r3, available at: http://www.opengeospatial.org/standards/sps (last access: 31 August 2010), 2005.

Spahn, H., Hoppe, M., Vidiarina, H. D., and Usdianto, B.: Experience from three years of local capacity development for tsunami early warning in Indonesia: challenges, lessons and the way ahead, Nat. Hazards Earth Syst. Sci., 10, 1411-1429, doi:10.5194/nhess-10-1411-2010, 2010.

Steinberg, A., Bowman, C., and White, F.: Revisions to the JDL data fusion model, The Joint NATO/IRIS Conference, Quebec, Canada, 1998.

Strunz, G. Post, J. Zosseder, K. Wegscheider, S. Mück, M. Riedlinger, T. Mehl, H. Dech, S. Birkmann, J. Gebert, N. Harjono, H. Anwar, H. Z., Sumaryono, Khomarudin, R. M., and Muhari, A.: Tsunami risk assessment for coastal areas in Indonesia, Nat. Hazards Earth Syst. Sci., in review, 2010.

UNESCO: Indian Ocean Tsunami Warning and Mitigation System (IOTWS), Implementation Plan for Regional Tsunami Watch Providers, UNESCO, IOC Information Series No. 81, 2008. 